\title{
Organizational Citizenship Behaviour and Demographic Factors among Oil Workers in Nigeria
}

\author{
Uzonwanne, Francis $\mathrm{C}$. $\mathrm{PhD}$ \\ Department of Psychology, College of Management Sciences, Redeemer's University Nigeria
}

\begin{abstract}
Even though numerous epidemiology studies have examined the patterns of mortality in refinery workers and petroleum distribution workers and even on production and pipeline workers whose primary exposure was to crude oil (Divine and Hartman, 2000), there is a dearth of research on the organizational citizenship behavior among these oil workers. This study seeks to fill the gap by investigating organizational citizenship behavior among oil workers in Nigeria and some demographic factors that determine this behavior among the workers. A power analysis on the OCB-C questionnaire to ensure that the statistical test will have adequate power resulted in a sample size of 120. 300 oil workers drawn from the major Petroleum Cooperation in Nigeria; Pipelines and Product Marketing Co-operation (P.P.M.C), MOSIMI which is a subsidiary of Nigerian National Oil Co-operation (N.N.P.C) were randomly selected for this study. The study set out to determine a significant difference in the organizational citizenship behaviour exhibited by these oil workers based on demographic variables, gender, educational level, and marital status. Findings showed that none of these demographic variables were a determinant factor on the display of organizational citizenship behavior of the oil workers which were actually consistent with existing literature. Findings may be useful in further understanding the role of education, gender and marriage among individuals who seek or hold sensitive positions in significant economical organizations with both the private and public sectors.
\end{abstract}

Keywords: Organizational Citizenship Behavior, Gender, Education, Marital Status

\section{Introduction}

It is evident that the sphere of oil drilling and general production is at the helm of the Nigerian economy as at the time of this study. Serving as the economic center of the nation, the workers in the oil sector are expected to be highly efficient, effective and productive. Even though recent literature express concern on the rigors of growing strong and effective teams (Edmondson, 2012), teams have been identified as very efficient, effective and a must have for every organization that seeks the peak of performance abilities. However, the organization has to play a major role in satisfying and motivating its employees as they are highly significant and their effort or job performance goes a long way in affecting the economic stamina of the country. Since oil is the major source of income in Nigeria, researchers cannot pay too much attention on the employees working under this sector. Organizational Citizenship Behavior is the individual behavior that is discretionary, not directly or explicitly recognized by the formal reward system, and that in the aggregate promotes the effective functioning of the organization (Organ 1988 \& 1997). In this view, engagement in Organizational Citizenship Behavior is generally a personal choice, and omission is not generally seen as punishable (Organ, 1988) but however, should be encouraged for greater effectiveness and growth in any organization. Work associations or organizations are for the most part acknowledged to be essential social settings where rivalry, rare assets, time limits, contrasts in objectives and identities and other sort of anxieties can lead workers to aggress against their colleagues, subordinates and even bosses (Aquino and Thau, 2009). However, within this competitive atmosphere, there are still some employees who find it necessary out of their own volition to help their colleague. They go out of their way to lend a helping hand to colleagues who may or may not require assistance in carrying out their day-to-day routine tasks without requesting for any form of recognition or additional pay from the organization. This helpful gesture can be said to be a "sense of Citizenship" or "organizational citizenship behavior" which translates into willingness to go beyond cultural obligation required by the organization of the employee. Researchers have continually and endlessly tried to find factors that decrease or increase the likelihood of the practice of organizational citizenship behaviors by employees (Aquino and Thau, 2009).

Ever since the first documented research on OCB was carried out by Organ and colleagues in the 1980's, subsequent researchers have continued to carryout in-depth research on OCB itself and its determinants. That is factors that increase or decrease the likelihood of practicing Organizational Citizenship Behavior. This study therefore focuses on gender, education and marital status as possible determinants of practicing Organizational Citizenship Behavior among oil workers in Nigeria. 
Subsequent definitions of Organizational Citizenship Behavior do not deviate much from the original definition, also there is much consistency found in their ways of interpreting OCB (Organ \& Koyovsky, 1989). For instance, (Kumar, Bakshi \& Rani, 2009) defines Organizational Citizenship Behavior as behaviors without a reward, expectation or requiring any punishment is called as Organizational Citizenship Behavior in an organization. Similarly, Hunt (2002) states that Organizational Citizenship Behavior are the individual behaviors of willingness, not based on orders, and increasing organizational performance. It can be observed that all the definitions emphasize on the employees willingness, secondly, it is an informal behavior and thirdly it is done to improve organizational effectiveness. According to Organ (1988), Most OCB activities, that are taken independently, would not make much impact on the general execution of the association. The impact will be seen with the total summation of all OCB performed crosswise over time and crosswise over persons in the gathering, division, and association in general. Originally, Smith et al. (1983) proposed a two-dimensional model of OCB: altruism and generalized compliance (later called conscientiousness). According to Redman \& Snape (2005), 'altruism' involves helping specific individuals in relation to organizational tasks. Altruism or helping coworkers makes the work framework more proficient and effective on the grounds that one worker can use his or her slack time (free time) to assist his or her colleague on a more urgent task (Yen \& Neihoff, 2004). Organ (1988) later expanded the taxonomy of OCB to include altruism, conscientiousness, sportsmanship, courtesy, and civic virtue.

Altruism - Behaviors that have the effect of helping specific others with a work-relevant problem.

Conscientiousness - Conscientiousness can be described as discretionary behaviors that go beyond the basic requirements of the job in terms of obeying work rules, attendance and job performance (Redman \& Snape, 2005).

Sportsmanship - Sportsmanship refers to individuals who tolerate the annoyances encountered in the place of work. Sportsmanship involves refraining from reporting trivial conflicts within the organization.

Courtesy - Courtesy refers to behaviors that are directed towards prevention of future problems.

Civic Virtue - Civic virtue refers to those behaviors that are concerned with the political life of the organization. It is concerned with the governance of the organization for instance attending meetings, engaging in policy debates among others.

However, Some researchers have differentiated the focal target of the OCB among the dimensions, such that OCB can be defined as pro-social or helping behavior directed at other coworkers (e.g., altruism and courtesy toward other individuals) or as pro-social behavior directed toward the employee's organization (e.g., sportsmanship, civic virtue, and conscientiousness in promoting the welfare of the organization) (Williams \& Anderson, 1991). Regarding the dimension of OCB toward the organization, majority of studies like that of Podsakoff, et al., (2000) have been devoted to the affiliative forms of such behavior (i.e., sportsmanship, compliance, conscientiousness), but a further distinction has been made that attends to a form of OCB that challenges the status quo of the organization (Podsakoff, et al., 2000) The term Organizational Citizenship Behavior cannot however be discussed without making mention of some concepts like job satisfaction and organizational commitment. Organ and Ryan's (1995) postulated that employee's attitudes: especially Job satisfaction and Job commitments can predict OCB better than dispositional variables. It is reasonable to suggest that Job satisfaction will positively relate to OCB. Employees who are satisfied with their job are likely to reciprocate with positive behaviors like OCB. Work satisfaction could be characterized as a pleasurable or positive enthusiastic /emotional state coming about as a result of the appraisal of one's employment or occupation encounters (Locke, 1976). Job satisfaction has the most robust attitudinal relationship with OCB (Organ and Ryan, 1995). Werner (2007) opines that only satisfied employees seem more likely to display positive behaviors that can effectively contribute to the overall functioning of the organization. Bateman and Organ (1983) also proposed that employees will tend to display organizational citizenship behaviors more probably when they feel satisfied with their jobs, against support or benefit (e.g., positive work experiences) provided by their organization or colleagues (Bateman and Organ, 1983). Even though this study is focused on demographic factors as a determinant of organizational citizenship behavior, organizational commitment is the relative strength of an individual's identification and involvement in a particular organization (Bateman and Organ, 1983). Also, organizational commitment alludes to and concentrates on the connection, emotionality and usefulness of the workers in the association (Bateman and Organ, 1983). Just like Job satisfaction, Organizational commitment is also often cited as an antecedent of OCB (Bateman and Organ, 1983). It is argued that committed employees are more likely to engage in behaviors that enhance their value and support the organization. Thus, a positive relationship between organizational commitment and OCB is reasonable.

\section{Gender and Organizational Citizenship Behavior}

Recent studies have generated interest in investigating the possibility that subtle discrimination exist such that men and women are rewarded differently in performance appraisal based on their participation in OCBs (Allen, 2004). This position is grounded in the assumption that women are expected to participate in 
certain dimensions of OCBs, whereas men are expected to participate in others. Gender influences the ways in which members of each gender are expected to behave and the manners in which their behavior is interpreted (Cooper et al, 2001). Treated as a personal characteristic, gender may influence an employee's perceptions of the workplace and their attitudinal reactions to others within an organization (Cooper et al, 2001). Furthermore, gender may affect whether individuals connect with coworkers who offer various kinds of information, social support, and opportunities (Cooper et al, 2001).

Research on gender differences has focused on two of Organs (1988) dimensions, in particular: helping and civic virtue. The helping dimension includes behavior that helps a specific other person (e.g. assisting others with their workloads). Researchers like Heilman and Chen (2005) pointed out that being a helper is central to female gender stereotype prescriptions, which dictate that women be nurturing and socially oriented (communal). On the other hand, the dimension of civic virtue includes behaviors that reflect responsible participation in, involvement with, and concern about the life of the employing organization (e.g. attending nonmandatory meetings) (Heilman and Chen, 2005). Civic virtue is considered agentic behavior (i.e. involving assertiveness ad independence), which is more consistent with prescriptions associated with the male gender stereotype (Heilman and Chen, 2005). This logic has led previous researchers to predict that helping behavior is more likely to be expected of women whereas civic virtue behavior is more likely to be expected of men (Heilman and Chen, 2005). However, some researchers have looked at the possibility that men and women are differently rewarded for participating in these dimensions of OCB (Allen, 2004; Heilman \& Chen, 2005). This could be the reason for the involvement of Organizational citizenship behavior by the two genders.

According to the research carried out by Langford \& MacKinnon (2000) Males deeply involved in OCBs may feel more obliged to engage their organization than females who are equally involved, as males may internalize the conviction that they should be loyal and assist their organization in achieving success (Langford \& MacKinnon, 2000). From an organizational perspective, males are generally stereotyped as being competent, assertive, independent, and achievement oriented (Langford \& MacKinnon, 2000). From an interpersonal perspective, females are generally stereotyped as warm, sociable, interdependent, and relationship oriented (Langford \& MacKinnon, 2000). Therefore, males highly involved in OCB may engage in more team effectiveness than females who are highly involved, indicating that gender stereotyping moderates relationships between OCBs and team effectiveness (Langford \& MacKinnon, 2000).

\section{Education and Organizational Citizenship Behavior}

Mohammad Amin et. al (2013) in their research failed to find a significant relationship between educational level and OCB. Their result found no statistical relationship between the both variables. Yaghoubi et al (2010) in their research also found out that educational status has no statistical relationship with OCB. Another study that carried out concluded that there is a meaningful negative relationship between OCB and its dimensions with educational level $(r=0.06)$ (Dolanet al, 2013). Furthermore, Nadiri \& Tanova(2010) in their research have showed that educational status has a positive and meaningful statistical relationship with $\mathrm{OCB}(\mathrm{r}=0.159, \mathrm{p}<0.05)$. With these general findings, one can conclude on inconsistencies, hence the need to investigate this particular group of employees.

\section{Marital Status and Organizational Citizenship Behavior}

Several researches have shown that there is no significant relationship between OCB and marital status. Mohammad Amin et. al (2013) stated in their study that married and single employees showed the same level of OCB in their work place. Yaghoubi et al (2010) in their research found out that marital status has no statistical relationship with OCB. Namazzi (2011) in a research study also stated that there is no significant relationship between OCB and marital status. Nevertheless, Iranzadeh and Asadi (2009) in their study among the employees of Mohagheghe Ardabili university have showed that marital status has statistical relationship with OCB. Again, inconsistencies can be identified with the existing literature that examines the relationships between marital status and organization citizenship behavior, providing strong reason for the need to explore different groups accordingly so as to avoid the pitfalls of generalization.

\subsection{Statement Of Problem}

It is paramount to note that the development of any society depends on its human and natural resources. Such human resources include the oil workers in any oil producing nation. These human resources are typically embedded within oil producing organizations. These are the set of people involve in the implementation of all rules and regulations and in carrying out work plan and work schedule. They shoulder many important and sensitivity work-related responsibilities, such as oil drilling and storage, heavy machinery maintenance, oil sales, ensuring safe delivery of merchandise, ensuring security of numerous pipelines against vandalisation and compromise, prevention of deep-sea oil spillage, accounting among so many other responsibilities. These oil workers also have to shoulder personal responsibilities like family issues and other interpersonal relationships 
among others. In Nigeria, an economy that is deeply dependent on oil resources, the continuous functionality of the oil sector is of utmost importance. In previous times and recently, disturbances in the functionality of the oil sector have resulted in unprecedented suffering on the Nigerian populace and such interruptions are not unconnected to the human resources involved in oil processes. Research focusing on the organizational citizenship behaviour of these oil workers is lacking and so is literature that investigates the determinants of this behaviour among the oil workers. This study seeks to contribute to the gap that has been identified in literature concerning OCB among oil worker by exploring some demographic factors as determinants of OCB.

\subsection{Research Hypotheses}

The following hypotheses were formulated to guide the focus of the current research.

1. Oil workers will significantly engage in organizational citizenship behavior based on their educational qualifications.

2. Unmarried oil workers will significantly engage in organizational citizenship behavior than married oil workers.

3. Female oil worker will significantly practice organizational citizenship behavior than male oil workers.

\section{Methodology}

This study seeks to examine some demographic factors that determine organizational citizenship behavior among oil workers in Nigeria. Research methodology refers to the overall method employed by the researcher to assemble data for the study with a view of arriving at a scientific conclusion.

\subsection{Research Design}

This study adopted a survey research design through the use of a psychological test, Organizational Citizenship Behavior checklist OCB-C and a structured questionnaire that collects demographic data, to examine the influence of demographic factors on the organizational citizenship behavior of selected oil workers in Mosimi, Ogun state, Nigeria. The independent variables are the demographic variables, gender, education and marital status, while the dependent variable is organizational citizenship behavior.

\subsection{Research Population And Sampling}

The survey population of this study consists of oil workers in Nigeria. An incidental sampling method was used to draw 300 samples from oil workers in Ogun state. The sample comprised of 151 females and 149 males. The oil workers were drawn from the major Petroleum Co-operation in Nigeria; Pipelines and Product Marketing Co-operation (P.P.M.C), MOSIMI which is a subsidiary of Nigerian National Oil Co-operation (N.N.P.C).

\subsection{Research Instrument} checklist.

The major instrument used for retrieving data in this study is the organizational citizenship behavior

\subsubsection{Organizational Citizenship Behavior-Checklist}

OCB-C questionnaire was developed by Suzy Fox and Paul Spector (2009) and is a 42-item instrument designed to assess the frequency of organizational citizenship behaviors performed by employees. It was then refined and shortened to 36 items and then finally to 20 items. The OCB-C was specifically designed to minimize overlap with scale of counterproductive work behavior. Fox and Spector (2009) obtained internal consistent reliability coefficient alpha of $\mathbf{. 8 9}$ and $\mathbf{. 9 4}$ for two self-report samples, and .94 for a coworker sample (coworkers reporting on the target employee). Fox and Spector (2009) reported a coefficient alpha of .91 and a concurrent validity of .83 for the scale.

The scoring technique for the OCB-C questionnaire follows a direct scoring pattern in which the scores are computed by summing responses across items. For example, if items 8910111213 where ticked as 2353 2 respectively, the score will be $2+3+5+3+2=15$

The items responses (Never, Once or twice, Once a month, Once or twice a week, Everyday) are scored as 1, 2, $3,4,5$ respectively.

The evaluation of the overall sum of each respondent as the higher the score the higher the level of OCB and the lower the score the lower the level of OCB.

\subsection{Method of Data Analysis}

The data that was collected for this study was processed manually through coding and then entered electronically into Statistical package for Social Sciences (SPSS) version 22. The use of statistical distributions 
such as tables and figures showing frequencies and percentages were adopted in the study. The hypotheses stated in the study were subjected to t-Test statistics for independent samples and One way ANOVA.

\subsection{Socio Demographic Data}

\section{Data Analysis And Results}

The demographic characteristics of the respondents in the studied population and variables like gender, marital status and highest educational qualification are analyzed and presented.

Table 1

Demographic Characteristics of Participants

\begin{tabular}{|l|l|l|l|l|}
\hline Variables & Number & Mean & SD \\
\hline \multirow{3}{*}{ Gender } & Male & 151 & 57.90 & 12.44 \\
\cline { 2 - 5 } & Female & 149 & 57.64 & 14.16 \\
\hline \multirow{3}{*}{ Marital Status } & Single & 95 & 58.43 & 11.58 \\
\cline { 2 - 5 } & Married & 193 & 58.04 & 13.64 \\
\hline \multirow{3}{*}{ Educ. Qual. } & Masters & 24 & 57.20 & 7.63 \\
\cline { 2 - 5 } & BSc/HND & 220 & 57.65 & 13.78 \\
\cline { 2 - 5 } & OND & 56 & 58.48 & 13.63 \\
\hline
\end{tabular}

There were 300 participants from an oil company surveyed on this study. From the Table 1, the gender distribution shows that 151 of the respondents are male and 149 are female and they have on average of 57.90 and 57.64 respectively on their Organizational Citizenship Behavior (OCB) scores with a standard deviation of 12.44 and 12.16 respectively. The marital status distribution shows that 193 of the respondents are married while 95 are single and they have on average of 58.04 and 58.43 respectively on their OCB scores with a standard deviation of 13.64 and 11.58 respectively. The highest educational qualification distribution shows that 24 of the respondents have a Masters degree and 220 of the respondents have either a Bachelors degree or a Higher National Diploma, 56 of them have an Ordinary National Diploma. They have an average of 57.20, 57.65 and 58.48 respectively on OCB scores with a standard deviation of 7.63, 13.78 and 13.63 respectively.

\subsection{Test Of Hypotheses}

The results for the three hypotheses tested for this study are presented in this section. The statistics include One Way Analysis of Variance and the t-Test statistics.

\subsubsection{Hypothesis One}

Oil workers will significantly engage on organizational citizenship behavior based on their educational qualifications.

A One-way Analysis of Variance (ANOVA was used to determine if there would be a difference in the OCB scores of oil workers with Masters Degrees, BSc/HND degree/diploma and OND certificates. The independent variable represented the three different educational qualifications, while the dependent variable was the oil workers OCB scores. See Table 2 for the means and standard deviations for each of the three groups of educational qualifications.

Table 2

Means and Standard Deviations of Standardized Test Scores

\begin{tabular}{llcc} 
Method & $n$ & Mean & SD \\
\hline Masters & 24 & 57.21 & 7.63 \\
BSc/HND & 220 & 57.65 & 13.78 \\
OND & 56 & 58.48 & 13.41 \\
Total & 300 & 57.77 & 13.30 \\
\hline
\end{tabular}

An alpha level.05 was used for all analyses. Table 4.5 shows the analysis of variance for the OCB scores of the oil workers based on their highest educational qualification. 
Table 3

\begin{tabular}{lccccc} 
Analysis of Variance For $O C B$ Scores & & & & \\
Source & $S S$ & $d f$ & $M S$ & $F$ & \\
\hline Between & & & & & \\
Within & 38.664 & 2 & 19.33 & .109 & .897 \\
Total & 52873.37 & 297 & 178.03 & & \\
\hline
\end{tabular}

There was no significant difference in the OCB of oil workers based on their level of education at the $\mathrm{p}<.05$ level for the three conditions $[\mathrm{F}(2,297)=.109, \mathrm{p}=0.897]$. Post hoc comparisons using the Tukey HSD test indicated that the mean score for the OCB of Masters degree holders $(\mathrm{M}=57.21, \mathrm{SD}=7.63)$ was not significantly different than that of $\mathrm{BSc} / \mathrm{HND}$ holders $(\mathrm{M}=57.65, \mathrm{SD}=13.78)$. It was also not significantly different from that of OND holders $(\mathrm{M}=58.48, \mathrm{SD}=13.41)$ which did not significantly differ from the OCB scores of BSc/HND holders either. Taken together, these results suggest that educational levels of the oil workers do not have an effect on their organizational citizenship behavior. Specifically, the results suggest that employees are capable of exhibiting organizational citizenship behaviour regardless of how educated they are or not.

\subsubsection{Hypothesis Two} oil workers.

Unmarried oil workers will significantly engage in organizational citizenship behavior than married

Table 4

$\mathrm{t}$-Test Table for the OCB scores of married and single oil workers

\begin{tabular}{|l|l|l|l|l|l|}
\hline MARITAL STATUS & $\mathbf{N}$ & MEAN & SD & t & P \\
\cline { 1 - 3 } MARRIED & 193 & 58.04 & 11.58 & \multirow{2}{*}{0.239} & \multirow{2}{*}{$>.05$} \\
\hline SINGLE & 95 & 58.43 & 13.64 & & \\
\hline
\end{tabular}

The t-Test scores showed that there were 193 married respondents and 95 single while the mean OCB score was 58.04 and 58.43 respectively. The two-tailed p value associated with this test was .811 . The t-Test failed to reveal a statistically reliable difference between the mean number of the OCB scores that the married oil workers has $(\mathrm{M}=58.04, \mathrm{~s}=11.58)$ and that of the single oil workers has $(\mathrm{M}=58.43, \mathrm{~s}=13.64), t(286)=$ $.239, p=.811, \alpha=.05$. It can be therefore concluded that the Organizational; Citizenship Behaviour of married oil workers is not different from that of the single oil workers.

\subsubsection{Hypothesis Three} workers.

Female oil worker will significantly practice organizational citizenship behavior than male oil

Table 5

t-Test Table for adolescents Gender and Psychological Health

\begin{tabular}{|l|l|l|l|l|l|}
\hline GENDER & N & MEAN & SD & t & P \\
\hline MALE & 151 & 57.90 & 12.44 & \multirow{2}{*}{0.171} & \multirow{2}{*}{$>.05$} \\
\hline FEMALE & 149 & 57.64 & 14.16 & & \\
\hline
\end{tabular}

The t-Test scores showed that there were 151 male respondents and 149 female while the mean OCB Score was 57.90 and 57.64 respectively. The two-tailed $p$ value associated with this test was .864 . The t-Test failed to reveal no statistically reliable difference between the mean number of the OCB scores that the male oil workers has $(\mathrm{M}=57.90, \mathrm{~s}=12.44)$ and that of the female oil workers has $(\mathrm{M}=57.64, \mathrm{~s}=14.16), t(298)=$ $.171, p=.864, \alpha=.05$. It can be therefore concluded that the Organizational Citizenship Behaviour of male oil workers is not different from that of the female oil workers.

\section{Discussion}

The objectives of the study were to examine selected demographic variables, gender, education and marital status as factors that determine organizational citizenship behavior among oil workers in Nigeria. 
Based on data generated by the study, it is reasonable to conclude that there is no significant difference in the organizational citizenship behaviour among the oil workers based on the selected demographics

The first hypothesis stated Oil workers will significantly engage on organizational citizenship behavior based on their educational qualifications. There was no significant difference in the OCB of oil workers based on their level of education at the $p<.05$ level for the three conditions $[F(2,297)=.109, p=0.897]$. Studies highlighting significant relationships between $\mathrm{OCB}$ and educational levels come back with mixed results. Mohammad Amin et. al (2013) in their research failed to find a significant relationship between educational level and OCB. Their result found no statistical relationship between the both variables. Yaghoubi et al (2010) in their research also found out that educational status has no statistical relationship with OCB. Another study that carried out concluded that there is a meaningful negative relationship between OCB and its dimensions with educational level $(\mathrm{r}=0.06)$ (Dolan et al, 2013). Furthermore, Nadiri and Tanova(2010) in their research have showed that educational status has a positive and meaningful statistical relationship with $\mathrm{OCB}(\mathrm{r}=0.159$, $\mathrm{p}<0.05)$. While the findings of this study are consistent with the findings of Yaghoubi et al (2010) and Mohammed Amin et al (2013), there are inconsistent with other findings (Dolan et al, 2013; Nadiri and Tanova, 2010). It cannot be ascertained why there is a difference in the findings, but it can be assumed that the differences can be situational or as a result of further job skill related training that the respondents have had to undergo.

The second hypothesis stated that Unmarried oil workers will significantly engage in organizational citizenship behavior more than married oil workers. The t-Test failed to reveal a statistically reliable difference between the mean number of the OCB scores that the married oil workers has $(\mathrm{M}=58.04, \mathrm{~s}=$ $11.58)$ and that of the single oil workers has $(\mathrm{M}=58.43, \mathrm{~s}=13.64), t(286)=.239, p=.811, \alpha=.05$. It can be therefore concluded that the Organizational; Citizenship Behaviour of married oil workers is not different from that of the single oil workers. This finding is also consistent with the findings from several other studies. For instance, Mohammad Amin et. al (2013) stated in their study that married and single employees showed the same level of OCB in their work place. Yaghoubi et al (2010) in their research found out that marital status has no statistical relationship with OCB. Namazzi (2011) in a research study also stated that there is no significant relationship between OCB and marital status. Nevertheless, Iranzadeh and Asadi (2009) in their study among the employees of Mohagheghe Ardabili university have showed that marital status has statistical relationship with OCB. This is a rather low relationship which cannot be ignored. The results however show that individuals are capable of exhibiting organizational citizenship behaviour regardless of their marital status. So the fact that one is married and must have learned some things about cohabitation does not influence their ability to exhibit OCB.

The third and final hypothesis stated that female oil worker will significantly practice organizational citizenship behavior more than male oil workers. Even though gender differences have been found for many variables, no statistically significant difference was found between the two gender components. Research on gender differences has focused on two of Organs (1988) dimensions, in particular: helping and civic virtue. The helping dimension includes behavior that helps a specific other person (e.g. assisting others with their workloads). Researchers like Heilman and Chen (2005) pointed out that being a helper is central to female gender stereotype prescriptions, which dictate that women be nurturing and socially oriented (communal). On the other hand, the dimension of civic virtue includes behaviors that reflect responsible participation in, involvement with, and concern about the life of the employing organization (e.g. attending non-mandatory meetings) (Heilman and Chen, 2005). Civic virtue is considered agentic behavior (i.e. involving assertiveness ad independence), which is more consistent with prescriptions associated with the male gender stereotype. This logic has led previous researchers to predict that helping behavior is more likely to be expected of women whereas civic virtue behavior is more likely to be expected of mean (Heilman and Chen, 2005). These findings imply that though male and females may defer in the type of citizenship behaviour they exhibit, they do not differ generally in the level of OCB they exhibit. This will be found to be consistent with the findings from this study.

\subsection{Summary}

The main purpose of this study was to examine selected demographic variables, gender, education and marital status as factors that determine organizational citizenship behavior among oil workers in Nigeria.

Quantitative data were analyzed using descriptive analysis, $t$-Test statistics and One-Way ANOVA. There were three hypotheses which were tested at 0.05 level of significance. The results show the following:

1. Oil workers significantly engage in organizational citizenship behavior based on their educational qualifications.

2. Unmarried oil workers do not significantly engage in organizational citizenship behavior than married oil workers. 
3. Female oil workers did not significantly practice organizational citizenship behavior than male oil workers.

\subsection{Conclusion}

The selected demographic variables, gender, education and marital status as factors that determine organizational citizenship behavior among oil workers in Nigeria is brought into focus in this study. Hypotheses focusing on comparison of OCB scores among these oil workers with related variables like gender, age and education are tested in this study. 300 respondents from Pipelines and Product Marketing Cooperation (P.P.M.C), MOSIMI which is a subsidiary of Nigerian National Oil Co-operation (N.N.P.C) were randomly sampled and data collected were subjected to descriptive statistics, t-Test and ANOVA. From the analysis and interpretation of results, it may be concluded that education, marital status and gender in this study were not found to have a significant difference in organizational citizenship behaviour.

\subsection{Implication Of Finding}

The implication of the findings of this study is that there is room for further research. The study was done in only one part of Nigeria and oil workers were surveyed from only one state. There are numerous oil stations, both on and off shore, in the six geo political and social regions of the country. The findings of the study can therefore not be taken as conclusive. Cultural and climate differences, to say a few, are capable of affecting the OCB of employees in other regions and even the stress and depression levels. In order to validate the findings of this study, there is therefore the need to replicate this study on other parts of the country, survey more oil workers and survey oil workers in various multi cultural environments. It may be necessary to include other variables also in the study. The working conditions may have reflected on both gender specifics the same way leaving little or no room for differences. This explanation can also be extended for the differences in educational qualification and marital status.

\subsection{Recommendation}

The following recommendations are made from the finding of this study to oil workers and authorities, researchers and other professionals and/or experts who work with such populations and variables. The incidence of marital status, educational qualification and gender on organizational citizenship behaviour should be de-emphasized while the emphasis should be on the antecedents of organizational citizenship behaviour and how to foster it in the workplace environment.

Managers must be aware of these OCB facilitators which can impact general team behaviour and eventually, organizational performance and productivity.

References

[1]. Allen, T.D. (2006). Rewarding good citizens: The relationship between citizenship behaviour, gender and organisational rewards. Journal of Applied Social Psychology, 36(1), 120- 143.

[2]. Aquino, K., \& Thau, S. (2009). Workplace victimization: Aggression from the target's perspective. Annual Review of Psychology, 60, 717-741.

[3]. Bateman, T. S., Organ, D. W. (1983). Job satisfaction and the good soldier: The relationship between affect and employee .citizenship. Academy of Management Journal, 26, 587- 59.

[4]. Cooper, C. L., Dewe, P., \& O'Driscoll, M. (2001). Organizational Stress: A review and critique of theory, research, and applications . Thousand Oaks: Sage.

[5]. Divine, B. J. \& Hartman, C. M. (2000). Update of a study of crude oil production workers 1946-94.Occupational Environmental Medicine, 57(6) pp:411-417

[6]. Edmondson, A. C. (2012). Teamwork on the fly. Harvard Business Review,5. Retrieved from http://hbr.org/2012/04/teamwork-onthe-fly/ar/1

[7]. Heilman, M. E. and Chen, J. J. (2005). Same behavior, different consequences: Reactions to men's and women's altruistic citizenship behavior. Journal of Applied Psychology 90, (3), pp: 431-441

[8]. Hunt, S. T. (2002). On the virtues of staying "inside the box": Does organizational citizenship behavior detract from performance in Taylorist jobs? International Journal of Selection and Assessment, 10, 152-159.

[9]. Iranzadeh, S., Asadi, N. (2009), The study of relationship of citizenship behavior and organizational justice with job happiness among the staff of Mohagheghe Ardabili university. Farasooye Modiriyat Journal, Vol. 3, No. 10, pp. 43-75.

[10]. Kumar, K., Bakshi, A., \& Rani, E. (2009). Linking the 'Big Five' personality domains to organizational citizenship behavior. International Journal of Psychological Studies, 2(1), 73-81

[11]. Langford, T. \& and Neil J. M. (2000). "The affective bases for the gendering of traits: Comparing the United States and Canada." Social Psychology Quarterly 63(1) pp: 34-48.

[12]. Locke, E. A., \& Latham, G. P. (1990). A theory of goal setting and task performance. Englewood Cliffs, NJ: Prentice Hall.

[13]. Mohammad Amin, B., Razieh M., Saeed H. G. \& Arefeh, D. T. (2014). Relationship between Organizational Perceived Justice and Organizational Citizenship Behavior among an Iranian hospital's employees. Electronic physician; 6 (2)

[14]. Organ, D.W. (1988). Organisational citizenship behaviour: The good soldier syndrome, Lexington, MA: Lexington Books.

[15]. Organ, D. W., Konovsky, M. (1989). Cognitive versus affective determinants of organizational citizenship behavior. Journal of Applied Psychology, 74(1), 157-164.

[16]. Organ, D. W. (1997). Organizational citizenship behavior: It's construct clean-up time. Human Performance, 10, 85-97. 
[17]. Organ, D. W., Podsakoff, P. M. and MacKenzie, S. B. (2006). Organizational Citizenship Behavior: Its Nature,Antecedents, and Consequences. Thousand Oaks, CA: Sage.

[18]. Podsakoff, P. M., MacKenzie, S. B., Paine, J. B., \& Bachrach, D. G. (2000). Organizational citizenship behaviors: A critical review of the theoretical and empirical literature and suggestions for future research. Journal of Management, 26, pp: 513-563.

[19]. Redman, T. \& Snape, E. (2005). Unpacking commitment: multiple loyalties and employee behaviour. Journal of Management Studies 42(2): 301-328.

[20]. Rousseau, D. M. (1989). Psychological and implied contracts in organizations. Employees Rights and Responsibilities Journal, 2 , $121-139$.

[21]. Smith, M., Saisan, J. \& Segal, J. (2014). Depression symptoms and warning signs. Retrieved from http://www.helpguide.org/mental.html

[22]. Williams, L. J., \& Anderson, S. E. (1991). Job satisfaction and organizational commitment as predictors of organizational citizenship and in-role behaviors. Journal of Management, 17, pp: 601-617.

[23]. Yaghoubi, M., Yarmohammadian, M.H., Raeisi, A.R., Javadi, M., Saghaiannejad, S. \& Isfahani, S. (2010), The Relationship between the Organizational Justice and Organizational Citizenship Behavior among Medical Records Staffs of Selected Hospitals of Isfahan. Health information management, special issue, pp. 506-515.

[24]. Yen, H. R. \& Niehoff, B. P. (2004). Organizational citizenship behaviors and organizational effectiveness: Examining relationships in Taiwanese banks. Journal of Applied Social Psychology, 34, (8), pp: 1617-1637. 